\title{
The relationship between voluntary employer change and work ability among older workers: investigating the honeymoon-hangover effect
}

\author{
Nina Garthe ${ }^{*}(\mathbb{D}$ and Hans Martin Hasselhorn (1)
}

\begin{abstract}
The aim of the study was to investigate the effect of voluntary employer changes on self-reported work ability among older workers in Germany and whether a honeymoon-hangover effect (HHE) exists here. In research on job satisfaction, three typical periods around a voluntary employer change characterize a HHE: a deterioration in the old job (deterioration), an initial increase in the new job (honeymoon) and a subsequent decline over time (hangover). Whether a HHE exists in respect to work ability following a voluntary employer change remained open. The analyses are based on data from the first three waves of the lidA study $(2011,2014,2018)$, a representative cohort study of older employees in Germany born in 1959 or 1965. Data from 2502 workers who participated in all three study waves was analyzed. Fixed-effects regression analyses including lag and lead variables were conducted. A deterioration, honeymoon and hangover period were found. Work ability increased substantially following the voluntary employer change. Our study shows that voluntary employer changes have the potential to maintain work ability at higher working age, but not to increase the work ability in the long-term perspective. However, despite the existence of a hangover period, the positive overall effect of the voluntary change should not be underestimated.
\end{abstract}

Keywords: Turnover, Older workers, Work ability, Honeymoon-hangover effect, Cohort study, Fixed-effects regression

\section{Introduction}

At times of worldwide extended working life policies, maintaining work ability at higher working age has received increased public and policy attention (Nilsson et al. 2011). Work ability can be defined as the result of the fit between the individual's resources and his or her work demands (Tuomi et al. 1997) and may answer the question 'How good is the worker at present, in the near future, and how able is he or she to do his or her work with respect to work demands, health, and mental resources?' (Tuomi et al. 1991). Therefore, work ability

\footnotetext{
*Correspondence: garthe@uni-wuppertal.de

Department of Occupational Health Science, School of Mechanical

Engineering and Safety Engineering, University of Wuppertal, Gaußstraße 20, 42119 Wuppertal, Germany
}

depends on the actual work situation (Frieling and Kotzab 2014) and is not limited to the individual worker's resources such as health and functioning (Ebener and Hasselhorn 2019). For over 30 years, work ability has been assessed worldwide with the work ability index (WAI), which has shown to predict various employmentrelated outcomes such as work motivation (Feißel et al. 2018), long-term sick leave, early exit from work and disability (Ebener and Hasselhorn 2019). Today, the WAI is used globally in occupational health practice to assess and maintain the workers' work ability (Bundesanstalt für Arbeitsschutz und Arbeitsmedizin 2013).

Strategies to sustain the fit between older workers and their work are needed as work ability often decreases with age (de Wind et al. 2015; Oakman et al. 2018). One strategy for older workers might be a voluntary change 
of employer, which enables the worker to leave unsuitable workplaces and thereby actively adapt unfavorable working conditions. The change bears the potential to attain suitable working conditions and to increase the ability to work longer at higher working age (Wilke et al. 2019).

The large body of research on voluntary employer changes mainly focuses on determinants such as job satisfaction, performance, health, leadership quality (see meta-analysis by Rubenstein et al. 2018) and also work ability (e.g. Rongen et al. 2014). The focus on determinants-in contrast to outcomes-was often due to limitations of the data, which did allow researchers to track employees up to the change, but not subsequently. Thus, there is still little research on the consequences of employer changes. The few previous studies confirm that voluntary employer changes have a positive effect on mental health (Liljegren and Ekberg 2009) and job satisfaction (Chadi and Hetschko 2014) and is associated with improved working conditions such as increased job security, reduced working hours (Carless and Arnup 2011), better salary, better possibilities for development and more appropriate work tasks (Grund 2009). To our knowledge, there is no scientific report about the effect on the workers' work ability.

In some studies, it was observed that the positive effects found following the employer change faded over time (Boswell et al. 2005, 2009, Chadi and Hetschko 2014). In theory, this phenomenon is called the honeymoon-hangover effect (HHE) (Boswell et al. 2005). Boswell et al. (2005) first described and examined the honeymoon-hangover effect in voluntary employer changes with respect to job satisfaction. According to the authors, three periods describe the honeymoon-hangover effect:

(1) In the first period, which may be called deterioration, employees experience a decline in job satisfaction in the old job. This job dissatisfaction precedes turnover.

(2) After turnover, job satisfaction strongly increases. This is referred to as the honeymoon period. The increase is explained by organizations creating an overly positive picture of the job for new hires, as well as the employee's tendency to portray the new organization in a positive light due to high expectations. Unfavorable information about the new job is suppressed.

(3) The initially high job satisfaction with the new job declines over time to an individual 'normal' level, which is called the hangover period. The longer tenure with the new job brings along increased knowledge of the organization and employees begin to recognize the less attractive aspects of the job; a subsequent disappointment and disillusionment.

The honeymoon-hangover effect was confirmed for job satisfaction in three different studies. Boswell et al. (2005) investigated the HHE by measuring job satisfaction in one-year intervals and found the three periods of the HHE in three to four subsequent years. In 2009, Boswell et al. conducted a similar study with four measurement points (day 1, 3 months, 6 months, 1 year). Within this year, they identified the periods honeymoon and hangover for job satisfaction. A third study by Chadi and Hetschko (2014) distinguished between employer changes due to quitting on own initiative, mutual agreement, dismissal and plant closure. They found a strong HHE for employees, who changed on own initiative and a slight HHE for employees, who changed due to mutual agreement. No HHE was found among employees, who changed due to dismissal or plant closure. Furthermore, Clark et al. (2008) found that life satisfaction significantly decreased before and increased after layoffs, but this increase was not longlasting. However, voluntary employer changes were not investigated.

Inspired by the studies on the HHE, we aimed to investigate the effect of voluntary employer changes on the work ability of older workers in Germany and whether HHE exist here. However, HHE may not develop in parallel for all possible outcomes (Roe 2008). Oakman et al. (2018), who investigated pathways of work ability over 6 years, state that sustained changes in work are required to change work ability and that these changes in work take time to make an impact. Thus, while an employer change may affect the course of job satisfaction immediately, this is followed by a readaptation after a shorter period of time. We suspect that for work ability, a longer time period is required for re-adaptation as the workers have to adapt to the new work situation, taking into account their health, competencies and values (Tuomi et al. 1997).

Now, the German lidA Cohort Study provides the opportunity to investigate the HHE for work ability among older workers in a large representative sample. In line with the theory on the honeymoon-hangover effect, we expect that the work ability of the employer changers is deteriorating in the old job and is therefore lower than the work ability after the change. Therefore, we postulate the following hypothesis:

Hypothesis 1 The work ability in the old job is deteriorating before a voluntary employer change (deterioration). 
Further, we expect an increase of the work ability following the employer change due to the new, probably more appropriate working conditions and the positive expectations in the new job:

Hypothesis 2 The work ability at the new job is initially higher than the work ability with the old job (honeymoon).

Lastly, we suppose that the higher work ability declines over time up to a level which is similar to the employees who have stayed with their employer, as the voluntary employer changers adapt to the new work situation and negative aspects of the job are also recognized.

Hypothesis 3 The initial high work ability in the new job will decline over time (hangover).

\section{Methods}

\subsection{Data and sample}

The data used for this study derive from the German lidA Cohort Study on Work, Age, Health and Work participation, a representative cohort study of older employees in Germany. Initially, employed people subject to social security contributions (no self-employed or sworn civil servants), born in either 1959 or 1965, are interviewed every three to four years in their homes (computerassisted personal interviewing, CAPI). The analyses are based on data from the first three waves of the study, $2011(n=6585), 2014(n=4244)$ and $2018(n=3586)$. In 2018, the participants were 53 and 59 years old. A more detailed description of the lidA Cohort Study and its design has been given elsewhere (Hasselhorn et al. 2014; Rauch et al. 2015).

For this study, participants were excluded if they were not employed full time, part time or marginally in any of the waves, if they were self-employed and if they had an involuntary change of employer between any of the waves. This balanced sample allows examination of intraindividual changes in work ability over the course of the three study waves. In all, 2502 workers were included who participated in all three study waves.

\subsection{Measures}

\subsubsection{Groups of voluntary employer change}

In wave two (2014) and three (2018), the participants were asked whether they changed employer on their own initiative. If the participants had multiple changes between two waves, only the last change was measured.

In the analyses we distinguish four groups: (1) participants, who had no change, either between 2011 and 2014 nor between 2014 and 2018, thus, they stayed in the same job for all three waves (Job A, Job A, Job A; AAA), (2) participants, who had no change between 2011 and 2014 and changed between 2014 and 2018, thus, they had a new job since wave 3 (Job A, Job A, Job B; AAB), (3) participants, who changed between 2011 and 2014 and had no change between 2014 and 2018, thus, they had a new job since wave 2 (Job A, Job B, Job B; ABB) and (4) participants, who changed between 2011 and 2014 and between 2014 and 2018, thus, they had new jobs in wave 2 and also in wave 3 (Job A, Job B, Job C; ABC).

\subsubsection{Work ability}

In each wave, work ability was measured by the second dimension (WAI2) of the Work Ability Index (WAI). The WAI is an established questionnaire to assess work ability in occupational health research. Short measures such as the WAI2, which assesses the work ability in relation to the demands of the job, were recommended for large surveys and shown to be suitable short measures for work ability in occupational health research and employee surveys (Ebener and Hasselhorn 2019). The WAI2 consists of three questions: In two questions the participants were asked to rate their actual work ability with respect to mental and physical demands at work, respectively (very poor/rather poor/moderate/rather good/very good). The answers were weighted depending on the third question, which measures whether the participant was mainly mentally active in the main job, mainly physically active or both equally. The weighting of the WAI2 is described by Hasselhorn and Ebener (2016). The resulting sum score ranges from 2 (no work ability) to 10 (high work ability).

\subsubsection{Socio-demographics}

Socio-demographic information includes gender (male/ female), year of birth (1959/1965), vocational education (low/medium/high) (based on Jöckel et al. 1998) as time-independent variables and having a partner (yes/no) assessed in each wave.

\subsubsection{Work factors}

The work factors include working hours (full time/part time/marginal employment), mental and physical work (mainly mental/mainly physical/both) and the income level (up to 1500 Euro/1500 to 3000 Euro/3000 Euro and more), each assessed in each wave.

\subsubsection{Health}

Mental and physical health were assessed with the Short Form Health Survey (SF-12) (Ware et al. 1995, Nübling et al. 2006). The component scores range from 0 to 100 with high scores indicating better health. Both SF-12 
scales were found to have acceptable psychometric properties and validity (Ware et al. 1996).

\subsubsection{Statistical analyses}

The analysis consists of two steps, the description and the regression analysis.

In the description, the four groups of voluntary employer change described above were compared in terms of socio-demographics, work factors, health and work ability across the three study waves. For work ability, the group means were displayed along with confidence intervals for each wave. This allows depicting the course of work ability for each group over time.

The regression analysis is conducted as a fixed effects regression analyses including lag and lead variables for employer changes in order to investigate the individual changes of work ability before and after a voluntary employer change. To examine the individual effect of voluntary employer changes, only participants who reported a change in one or more of the waves were included in the regression analyses. With the fixed effects transformation, the individual mean value for work ability over the three waves is subtracted from each single work ability score for each participant. Through this transformation, the individual relationship between the values of each participant remains the same, but potential level differences between the participants are eliminated. Therefore, the fixed effects regression analyses allow to investigate individual work ability changes and unobserved individual heterogeneity, i.e. level differences between study participants, is removed from the work ability data.

The honeymoon-hangover effect is examined by including lag or lead dummy variables for voluntary employer changes, respectively. The three study waves allow to integrate two lag variables, which indicate whether a participant has a new job since one or two waves (examining the honeymoon and hangover period, models 1 and 2). Similarly, two lead variables could be integrated, which indicate whether a participant will have a new job in one or two waves (examining the deterioration period, models 3 and 4). In Models 2 and 4 control variables are added. Sensitivity analyses were conducted by performing separate analyses for men and women and for participants born in 1959 and 1965.

All statistical analyses were performed using SPSS version 26.0.

\section{Results}

\subsection{Description}

Table 1 shows the socio-demographics, work factors, health and work ability in the total sample and across the change groups. The majority of the participants stayed with their employer over the seven years $(89.6 \%$;
$A A A) .9 .2 \%$ of the participants changed once $(A A B$, $A B B)$ and $1.2 \%$ changed twice $(A B C)$. In some aspects, these three change groups differed from the group of stayers. Women and the younger cohort born in 1965 were overrepresented in all change groups. Participants with medium educational level were overrepresented in groups $\mathrm{AAB}$ and $\mathrm{ABB}$ and participants with low educational level were overrepresented in group $A B C$. In all change groups, participants more often had a partner. Participants who changed once were less likely to work full-time in each of the waves. Only in wave one, those marginally employed were overrepresented among the three change groups. In wave three, participants working full-time were overrepresented in the ABC group. Furthermore, participants, who work mainly physically, were overrepresented among all change groups. After changing, these participants more often did both, physical and mental work. More participants with a low income changed employer voluntarily. Mental health increased after a voluntary change. In relation to the stayers, changers reported worse mental health before a change and better physical health afterwards.

Figure 1 displays the course of work ability for the four groups of voluntary employer change over time. The figure indicates different patterns for each groups' work ability: the work ability of the stayers (AAA) slightly deteriorated over time and the work ability of the group, who changed twice $(A B C)$, considerably improved after each change. The groups, who changed once (AAB, ABB), had reverse patterns. The work ability of group $\mathrm{ABB}$ initially improved following the change and then deteriorated considerably while staying with the new employer. The work ability of group $\mathrm{AAB}$ slightly deteriorated while staying with the old employer and improved following the change. Overall, these patterns indicate a honeymoon-hangover effect, as the work ability of the group $A A B$ deteriorated before the change (deterioration), the work ability of all change groups $(\mathrm{AAB}, \mathrm{ABB}, \mathrm{ABC})$ improved after the change (honeymoon) and the work ability of the group $\mathrm{ABB}$ deteriorated while staying with the new employer (hangover). This supports hypotheses 1,2 and 3 .

\subsection{Regression analyses}

The regression analysis provides further insight into the honeymoon-hangover effect, while controlling for socio-demographic information and work factors. The fixed-effects transformation of the outcome work ability allows prediction of the individual changes of work ability, as positive values do not indicate high work ability, but higher work ability in relation to another observation of the same individual. In all models, only 


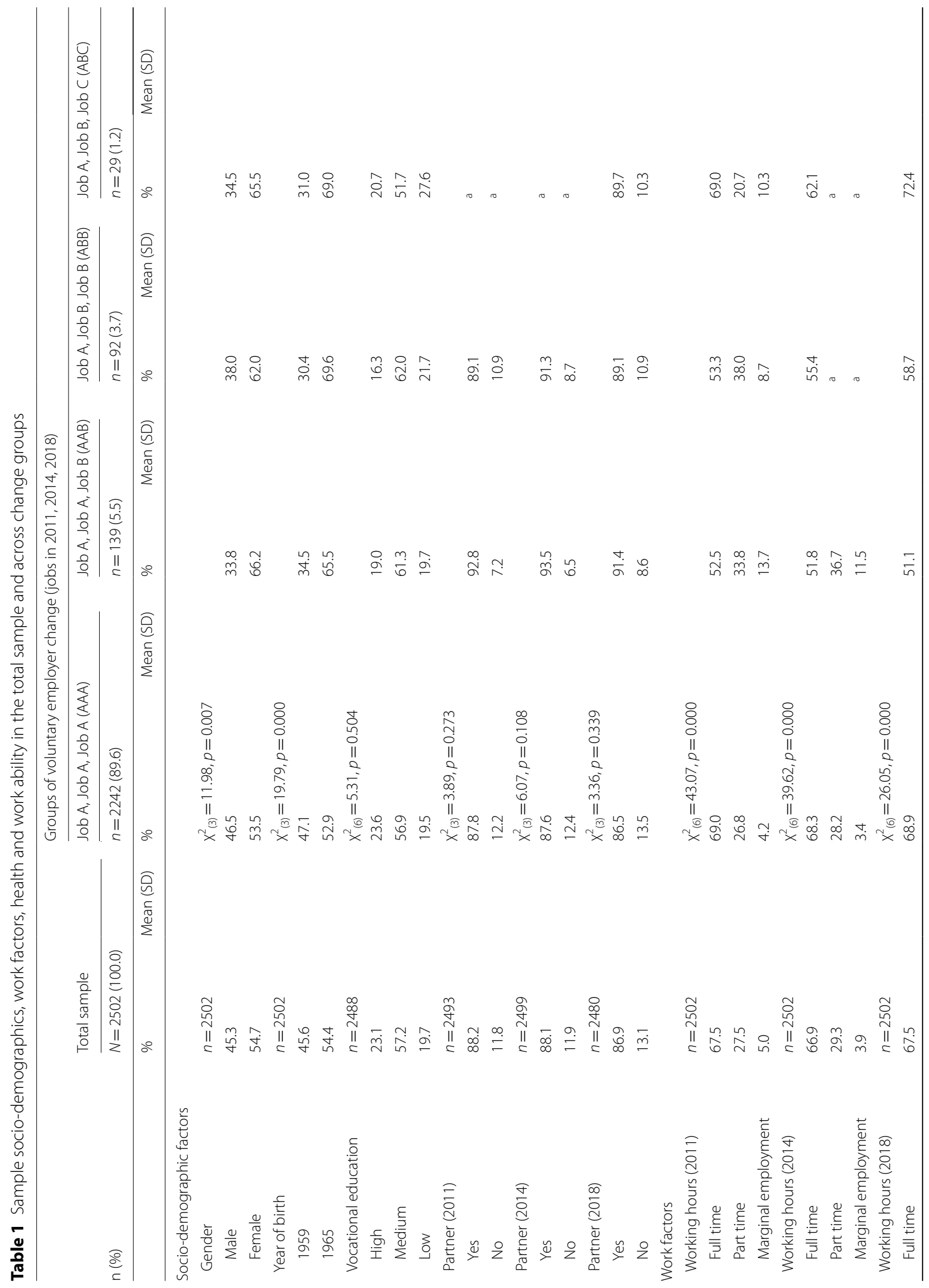




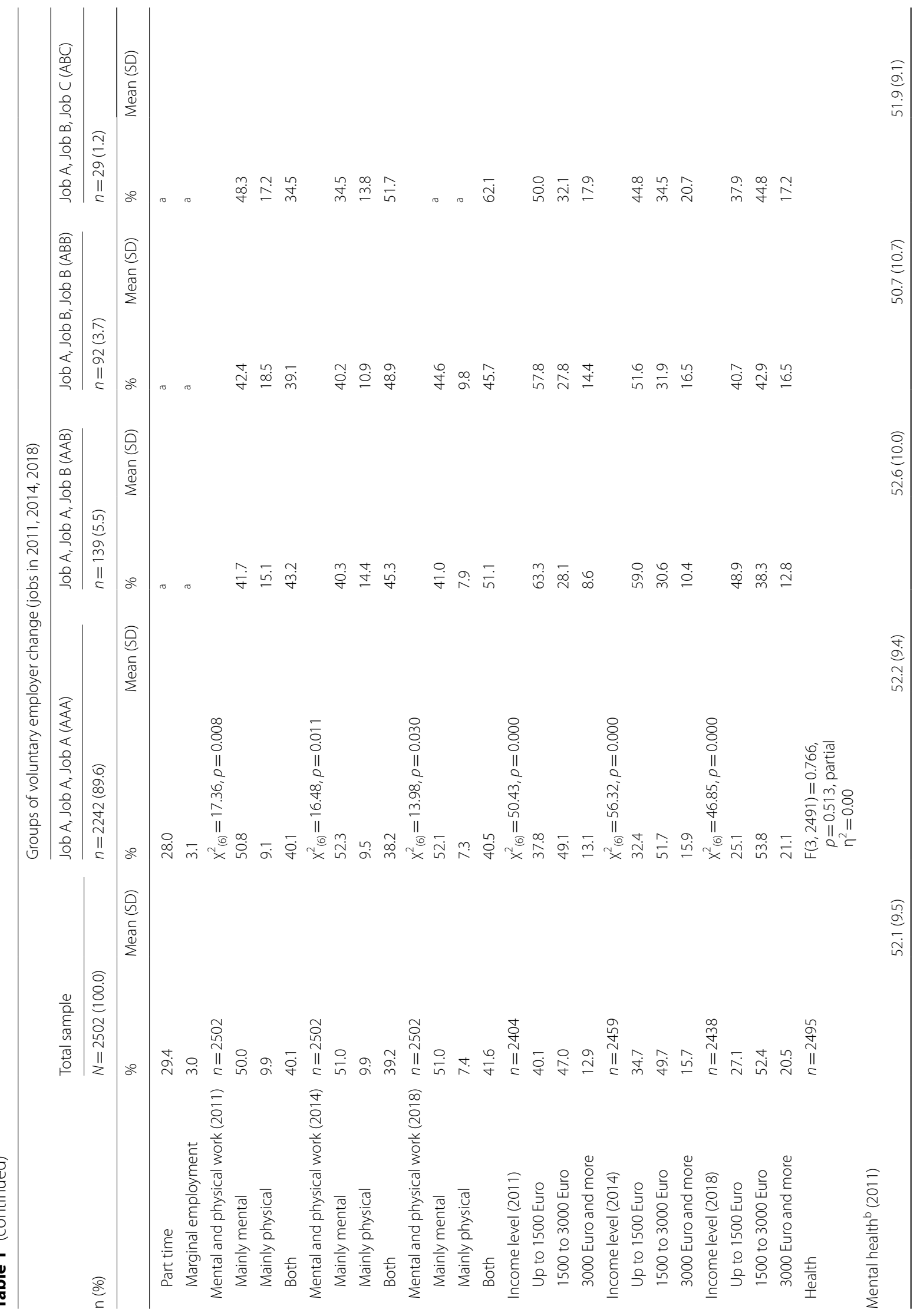




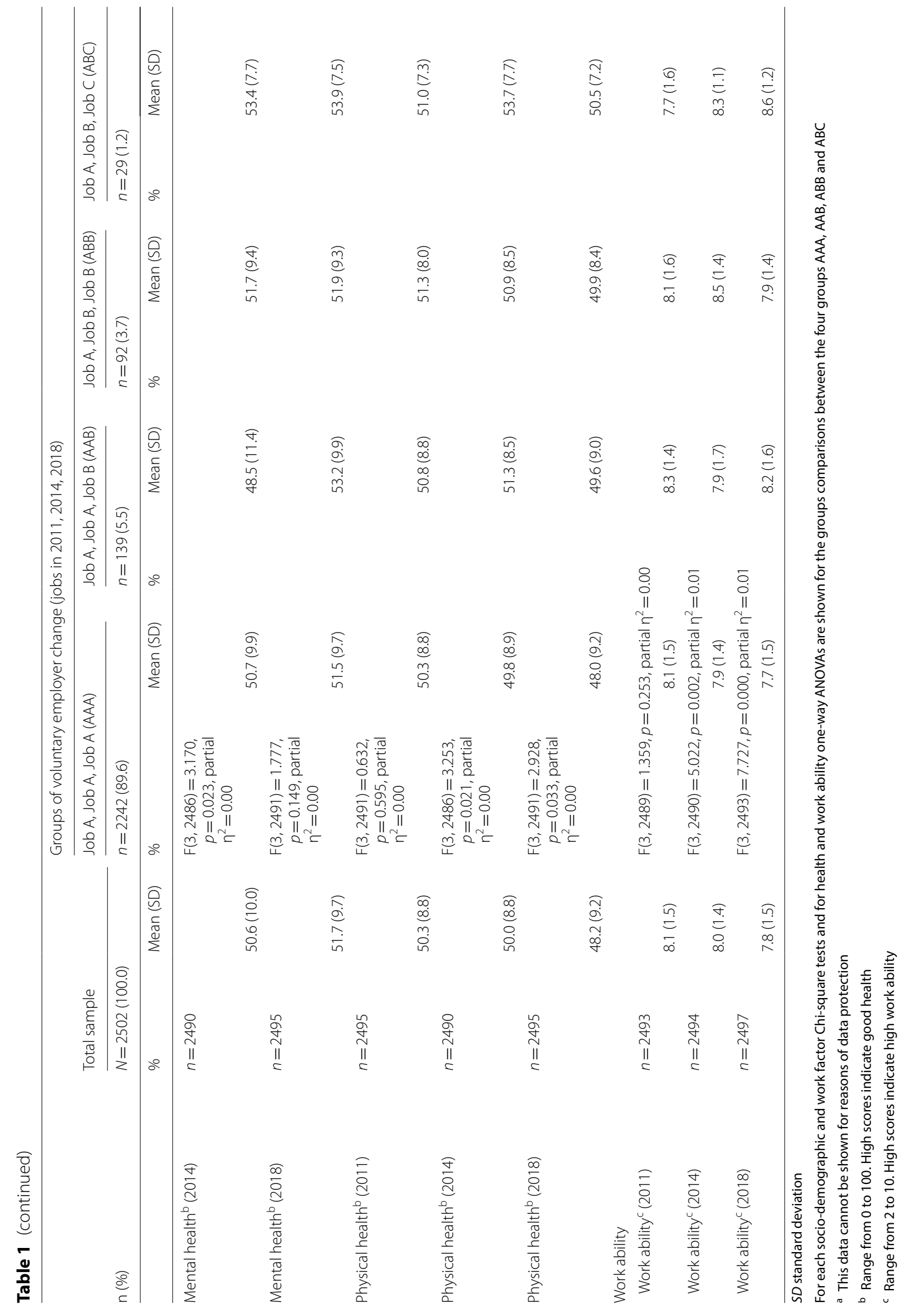




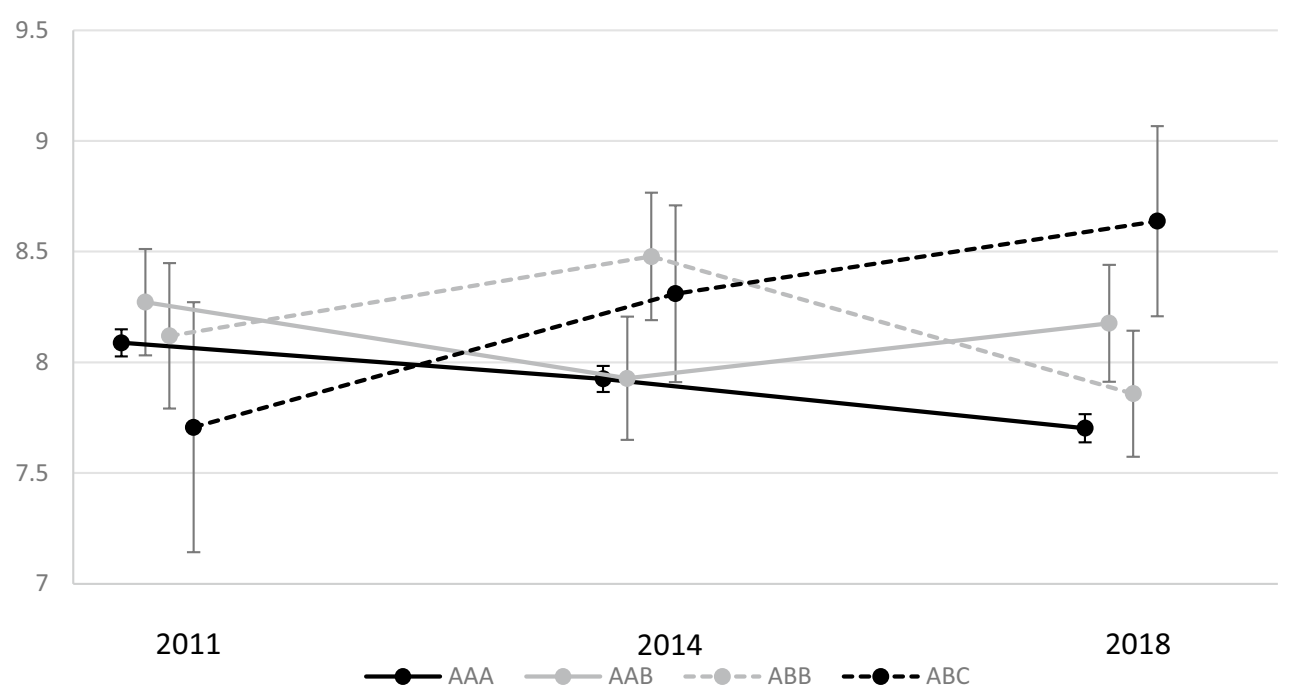

Fig. 1 Work ability of voluntary employer changers between 2011 and 2018 with confidence intervals (2011: $n=2493,2014: n=2494,2018$ : $n=2497$ ). Notes: Possible range from 2 (no work ability) to 10 (maximal work ability). AAA: Job A, Job A, Job A ( $n=2234-2237$ ); AAB: Job A in 2011, Job A in 2014, Job B in 2018 ( $n=138-139) ; A B B:$ Job A in 2011, Job B in 2014, Job B in 2018 ( $n=92)$; ABC: Job A in 2011, Job B in 2014 , Job C in 2018 $(n=29)$

observations of participants reporting a change (groups $\mathrm{AAB}, \mathrm{ABB} ; \mathrm{ABC}$ ) were included (Table 2).

Models 1 and 2 include the two lag variables, which allow to investigate the effect of being in a new job since one or two waves on work ability. The two lag variables are dummy variables indicating if a participant was in a new job since one or two waves, respectively. The models show that the work ability in the new job was significantly higher one wave after the change. The lag variable 'new job since 2 waves' showed no significant effect, which indicates that the work ability was not significantly higher two waves after the change. This supports hypotheses 2 and 3 and the existence of a honeymoon and hangover period.

Models 3 and 4 include the two lead variables, which allow to examine if and how the individual work ability before changing the employer differed from work ability following the change. The two lead variables are dummy variables indicating if a participant will be in a new job in one or two waves, respectively. The models show that work ability in the wave prior to the change was significantly lower than after the change, which is indicated by the negative regression coefficient. The lead variable 'new job in 2 waves' showed no significant effect. This result supports hypothesis 1 and the deterioration period, as the work ability one wave before the change was significantly lower than after the change (significant negative regression coefficient), but not two waves before (no significant regression coefficient).
The inclusion of control variables in models 2 and 4 did not affect these results. In the sensitivity analyses (not shown), similar patterns as described above were found for men and women, participants born in 1965 and 1959 and when including the observations of all participants (groups $\mathrm{AAA}, \mathrm{AAB}, \mathrm{ABB}$ and $\mathrm{ABC}$ ) in the regression analyses. However, significant regression coefficients were only found for women and younger workers, which may be due to the low number of cases among male participants and participants born in 1959 reporting a voluntary employer change. In further sensitivity analyses covering not only those who changed job but all participants $(n=2479)$ and observations $(n=7437)$, the findings and significances remained largely stable. However, the corrected within $\mathrm{R}^{2}$ was considerably lower which may be explained by a dilution effect due to the-logically-reduced within-panel variation of the lag and lead variables.

\section{Discussion}

In summary, our data indicate that voluntary employer changers are a specific group of employees among older workers. In this study younger and female employees were overrepresented among changers. The higher proportion of female changers may be due to the fact that women are more likely to work in jobs with more opportunities and needs to change employer. For example, in part-time and marginal employment, in jobs with a lower income level and in occupations which more easily allow 
Table 2 Fixed effects regression analyses. Work ability before and after voluntary employer change

\begin{tabular}{|c|c|c|c|c|}
\hline & Model 1 & Model 2 & Model 3 & Model 4 \\
\hline \multicolumn{5}{|l|}{ Leads } \\
\hline New job in 2 waves & & & -0.005 & -0.005 \\
\hline New job in 1 wave & & & $-0.114^{* *}$ & $-0.106^{* *}$ \\
\hline \multicolumn{5}{|l|}{ Lags } \\
\hline New job since 1 wave & $0.132^{* * *}$ & $0.135^{* * *}$ & & \\
\hline New job since 2 waves & -0.038 & -0.039 & & \\
\hline \multicolumn{5}{|c|}{ Working hours (Ref.: full time) } \\
\hline Part time & & 0.005 & & 0.009 \\
\hline Marginal employment & & 0.015 & & 0.012 \\
\hline \multicolumn{5}{|c|}{ Mental and physical work (Ref.: mainly mental) } \\
\hline Mainly physical & & -0.059 & & -0.055 \\
\hline Both & & 0.006 & & 0.015 \\
\hline \multicolumn{5}{|c|}{ Income level (Ref.: 1500-3000 Euro) } \\
\hline Up to 1500 Euro & & -0.004 & & -0.003 \\
\hline 3000 Euro and more & & -0.016 & & -0.008 \\
\hline Number of observations & 777 & 750 & 777 & 750 \\
\hline Number of individuals & 259 & 250 & 259 & 250 \\
\hline Corrected within $\mathrm{R}^{2}$ & 0.017 & 0.015 & 0.010 & 0.005 \\
\hline
\end{tabular}

Regression coefficients: Standardised beta $(\beta) .{ }^{*} p<0.05,{ }^{* *} p<0.01,{ }^{* * *} p<0.001$. Only participants reporting a change were included

for changes such as social and health care professions. Many changers seem to leave marginal employment over time and tend to change to full-time employment. Also, a higher proportion of employees with low or medium vocational education and mainly physical work changed employer voluntarily; groups with a higher risk for early retirement in Germany (Brussig 2015). Moreover, employees with a lower income level, a partner and better physical health changed more frequently.

The work ability patterns over time shown in Fig. 1 and the regression analyses supported all three hypotheses: (1) The work ability in the old job had deteriorated before a voluntary employer change, (2) the work ability at the new job was initially higher than the work ability with the old job, and (3) the initial high work ability at the new job declined over time.

\subsection{The role of time}

Our findings confirm that the time interval matters. Boswell et al. (2005), who investigated the HHE for job satisfaction, measured job satisfaction in five consecutive years and found a deterioration period two years before the employer change, a honeymoon period in the assessment one year after the change and a hangover period one year later. In our study, we also found an HHE, although work ability was measured in three- to four-year periods. Roe (2008) assumed that the time period until the onset of effects can widely differ. In our case, employer changes may have an immediate impact on some and a delayed effect on other outcomes. We suppose the latter when it comes to work ability. This is because the employer change may go along with many small changes in work and private life to which the employees have to adapt to and which are eventually integrated into everyday life. For example, the new job may require shorter commuting allowing for more time at home, for hobbies, friends, household and sports. It may therefore have a positive effect on leisure activities, physical and mental health and life satisfaction, which, in turn, increase resilience to stress and workload.

\subsection{The honeymoon-hangover effect for work ability}

In theory, the honeymoon-hangover effect constitutes three periods, deterioration, honeymoon and hangover (Boswell et al. 2005). In our study, we identified a deterioration period for work ability. However, the work ability prior to changes (in $\mathrm{AAB}$ and $\mathrm{ABB}$ ) was not significantly lower than that of the stayers (AAA, see Fig. 1). Therefore, low work ability does not seem to be a primary reason for a voluntary employer change among older workers, unlike job satisfaction as indicated by most of the turnover theories and models (see review by Hom et al. 2017). To what extent the deterioration period can be attributed to poor working conditions or age effects, remains open. Nevertheless, Garthe and Hasselhorn (2020) showed that older voluntary employer changers reported significantly worse psychosocial working 
conditions before their change than stayers indicating a strong impact of work.

Furthermore, we confirmed the existence of a honeymoon period for work ability. Work ability improved substantially following a voluntary change of employer. Theory on the honeymoon-hangover effect explains the honeymoon period for job satisfaction by the assumption that the new organization creates an overly positive picture of the job and that the employees portray the new organization in a positive light (Boswell et al. 2005). Yet, we suppose that there is more to it than that, when it comes to work ability. Many working conditions can change due to a voluntary employer change, which may have a direct impact on work ability-and of course job satisfaction-such as leadership quality, work-privacy conflict, travel time to work, colleagues, work tasks, influence at work, working environment and work equipment (Grund 2009; Carless and Arnup 2011; Garthe and Hasselhorn 2020). Several studies confirmed the relationship between physical and psychological working conditions and work ability (Alavinia 2008; van den Berg et al. 2008; Sanders et al. 2011; Attarchi et al. 2014; Weale et al. 2019). It can also be assumed that only those employees change, who expect an improvement, which implies that changers to some degree may constitute a selective group. Thus, there may be real positive changes in work that can cause a honeymoon period; it is not just a question of perception.

Although we assume that the voluntary change actually improves the work situation, we found a hangover period for work ability. Figure 1 depicts (see pattern of $\mathrm{ABB}$ ), and the regression analysis confirms that voluntary employer changes had a strong positive effect on the work ability in the following wave, which did not hold until the next wave. As assumed in theory, the adaption to the new job, the routine, the knowledge of the organization and the negative aspects of the job appear with time and may affect the self-reported work ability as well (Boswell et al. 2009). We suppose that this hangover period cannot be explained solely by age effects, as the self-reported work ability deteriorates strongly to a 'normal' level after the honeymoon period within four years. Furthermore, we did not find a hangover period among the participants who changed twice $(\mathrm{ABC})$. In contrast to the single time changers, this group seems to experience another honeymoon period. Gielen (2013) examined the relationship between repeated job quits and job satisfaction in men and found a strong increase of job satisfaction after each employer change and a slight decrease in job satisfaction, when the participants stayed with the new employer. She concludes that most of the repeated job quits were stepping stones to find the most preferred job. For our study, we cannot exclude a hangover period for these participants when they stay for a longer period of time with their current employer.

In conclusion, although we detected a hangover period, we suppose that the change was not in vain and is a strategy to maintain work ability at higher working age for three reasons. First, a voluntary change actually goes along with improvements of working conditions and work ability. Second, the voluntary change has the potential to induce a better match between the work and the aging workers, whose health and work ability are likely to deteriorate at higher working age (Frieling and Kotzab 2014). Third, we assume that the changers might have experienced a considerable deterioration in their work ability if they had not taken the opportunity to change. Studies on job lock and stuck at work showed that workers' health and job satisfaction deteriorated over time while staying with a non-desired employer (Huysse-Gaytandjieva et al. 2013; Canivet et al. 2017).

\subsection{Limitations}

In addition to its strengths, this study also has limitations. First, we had no data on work ability before 2011 and after 2018 to investigate the work ability pattern of the changers two periods before or after the change. Second, we only had data with a 3- and a 4-year period between waves and could not investigate in-between changes in work ability. Third, we could not exclude selection effects, because we only included employees, who participated in all three waves.

\section{Conclusions}

Maintaining the work ability of older employees is relevant for the society and the employers, who will be increasingly dependent on older workers and certainly for the older employees themselves, who want to, or have to work longer. Our study shows that voluntary employer changes have the potential to maintain work ability at higher working age, but not to increase work ability longlasting. We found a honeymoon-hangover effect for work ability, meaning a substantial increase of work ability shortly after the change and a decrease of the work ability over time, while staying with the new employer. On the one hand, our analyses suggest that the increase of work ability should not be overestimated in its duration or sustainability. On the other hand, the findings indicate that despite the decrease in the work ability, the potential positive overall effect of the voluntary change should not be underestimated.

Our study is the first to investigate the consequences of voluntary employer changes on older workers' work ability. Future studies should examine in depth, why there is a hangover period, while staying with the new employer, although real improvements in working conditions can 
be expected. Another question is, if the changers' work ability remains higher than the work ability of the stayers over time. Further, shorter time intervals should be considered to investigate short-term effects. In addition to the employer changers, employees who are stuck at their work and employer, need to be investigated over time, because among them a stronger decrease in work ability can be expected than among employees, who voluntarily stay with their employer.

\begin{abstract}
Abbreviations
HHE: Honeymoon-hangover effect; AAA: Job A, Job A, Job A (in the years 2011, 2014 and 2018); ABB: Job A, Job B, Job B (in the years 2011, 2014 and 2018); AAB: Job A, Job A, Job B (in the years 2011, 2014 and 2018); ABC: Job A, Job B, Job C (in the years 2011, 2014 and 2018).
\end{abstract}

\section{Acknowledgements}

The authors wish to thank the academic contributor Michael Stiller for discussions of the methods used.

\section{Authors' contributions}

NG conceptualized und wrote the manuscript, analyzed and interpreted the data. $\mathrm{HMH}$ contributed to the interpretation of the data and the writing of the manuscript. Both authors have read and approved the final manuscript.

\section{Funding}

This work was supported by the Minister of Culture and Science of the German State of North Rhine-Westphalia; and the German Social Accident Insurance, DGUV (FP 403). The funding institutions did not have any influence on the design of the study, the data collection, analysis and interpretation of the data nor on the writing of the manuscript.

\section{Availability of data and materials}

The datasets used for the current analysis are not publicly available due to protection of data privacy (www.lida-studie.de). A Scientific Use File will be available in 2023.

\section{Declarations}

\section{Competing interests}

The authors declare that they do not have competing interests.

Received: 5 June 2020 Accepted: 3 April 2021

Published online: 18 April 2021

\section{References}

Alavinia, SM: The Effect of Work on Health and Work Ability: De invloed van werk op gezondheid en werkvermogen. Dissertation, Erasmus Universiteit Rotterdam (2008)

Attarchi, M., Ghaffari, M., Abdi, A., Mirzamohammadi, E., Seyedmehdi, S.M., Rahimpour, F., Fazlalizadeh, M., Mohammadi, S.: Assessment of the relationship between physical working conditions and different levels of work ability. Glob. J. Health Sci. 6(4), 213-220 (2014). https://doi.org/10. 5539/gjhs.v6n4p213

Boswell, W.R., Boudreau, J.W., Tichy, J.: The relationship between employee job change and job satisfaction: the honeymoon-hangover effect. J. Appl. Psychol. 90(5), 882-892 (2005). https://doi.org/10.1037/0021-9010.90.5. 882

Boswell, W.R., Shipp, A.J., Payne, S.C., Culbertson, S.S.: Changes in newcomer job satisfaction over time: examining the pattern of honeymoons and hangovers. J. Appl. Psychol. 94(4), 844-858 (2009). https://doi.org/10. 1037/a0014975
Brussig, M.: Working conditions in the last job and transitions into old-age pensions: an analysis of two pension entry cohorts in Germany. Work Aging Retire 2(1), 54-64 (2015). https://doi.org/10.1093/workar/wav016

Canivet, C., Aronsson, G., Bernhard-Oettel, C., Leineweber, C., Moghaddassi, M., Stengård, J., Westerlund, H., Östergren, P.-O.: The negative effects on mental health of being in a non-desired occupation in an increasingly precarious labour market. SSM Popul. Health 3, 516-524 (2017). https:// doi.org/10.1016/j.ssmph.2017.05.009

Carless, S.A., Arnup, J.L.: A longitudinal study of the determinants and outcomes of career change. J. Vocat. Behav. 78(1), 80-91 (2011). https://doi. org/10.1016/j.jvb.2010.09.002

Chadi, A., Hetschko, C.: The magic of the new: How job changes affect job satisfaction. IAAEU Discussion Paper Series in Economics 05, 1-36 (2014). https://doi.org/10.1111/jems.12217

Clark, A.E., Diener, E., Georgellis, Y., Lucas, R.E.: Lags and leads in life satisfaction: a test of the baseline hypothesis. Econ J 118(529), F222-F243 (2008). https://doi.org/10.1111/j.1468-0297.2008.02150.x

de Wind, A., Geuskens, G.A., Ybema, J.F., Bongers, P.M., van der Beek, A.J.: The role of ability, motivation, and opportunity to work in the transition from work to early retirement-testing and optimizing the Early Retirement Model. Scand. J. Work Environ. Health 41 (1), 24-35 (2015). https://doi.org/ 10.5271/sjweh.3468

Ebener, M., Hasselhorn, H.M.: Validation of short measures of work ability for research and employee surveys. Int J Environ. Res. Public Health 16(18), 1-15 (2019). https://doi.org/10.3390/ijerph16183386

Feißel, A., Swart, E., March, S.: The impact of work ability on work motivation and health: a longitudinal study based on older employees. J. Occup. Environ. Med. 60(5), e238-e244 (2018). https://doi.org/10.1097/JOM. 0000000000001244

Frieling, E., Kotzab, D.: Work-Ability-Index—eine vergleichende Darstellung des Altersgangs in verschiedenen Tätigkeitsbereichen: Automobilmontage. Berufsfeuerwehr und Pflegetätigkeiten Z Arb Wiss 68, 19-25 (2014). https://doi.org/10.1007/BF03374418

Garthe, N., Hasselhorn, H.M.: Leaving and staying with the employerchanges in work, health, and work ability among older workers. Int. Arch. Occup. Environ. Health 94(1), 85-93 (2020). https://doi.org/10.1007/ s00420-020-01563-0

Gielen, A.C.: Repeated job quits: stepping stones or learning about quality? IZA J. Labor. Stud. 2(7), 1-22 (2013). https://doi.org/10.1186/2193-9012-2-7

Grund, C.: Jobpräferenzen und Arbeitsplatzwechsel. Z. Pers. 23(1), 66-72 (2009)

Hasselhorn, HM, Ebener, M: Der Work Ability Index in der Betriebsmedizin. In: Letzel, S, Nowak, D (eds) Handbuch der Arbeitsmedizin: Arbeitsphysiologie, Arbeitspsychologie, klinische Arbeitsmedizin, Prävention und Gesundheitsförderung, 3rd edn., 1-16. ecomed Medizin, Landsberg am Lech (2016)

Hasselhorn, H.M., Peter, R., Rauch, A., Schröder, H., Swart, E., Bender, S., Du Prel, J.-B., Ebener, M., March, S., Trappmann, M., Steinwede, J., Müller, B.H. Cohort profile: The lidA cohort study - a German cohort study on work, age, health and work participation. Int. J. Epidemiol. 43(6), 1736-1749 (2014). https://doi.org/10.1093/ije/dyu021

Hom, P.W., Lee, T.W., Shaw, J.D., Hausknecht, J.P.: One hundred years of employee turnover theory and research. J. Appl. Psychol. 102(3), 530-545 (2017). https://doi.org/10.1037/apl0000103

Huysse-Gaytandjieva, A., Groot, W., Pavlova, M.: A new perspective on job lock. Soc. Indic. Res. 112(3), 587-610 (2013). https://doi.org/10.1007/ s1 1205-012-0072-2

Jöckel, K-H, Babitisch, B, Bellach, B, Bloomfield, K, Hoffmeyer-Zlotnik, J, Winkler, $J$. Messung und Quantifizierung soziographischer Merkmale in epidemiologischen Studien. In: Ahrens, W, Bellach, B, Jöckel, K-H, editors Messung soziodemographischer Merkmale in der Epidemiologie: RKI-Schrift 1/98. MMV Medizin Verlag, München (1998)

Liljegren, M., Ekberg, K.: Job mobility as predictor of health and burnout. J. Occup. Organ. Psychol. 82(2), 317-329 (2009). https://doi.org/10.1348/ 096317908X332919

Nilsson, K., Hydbom, A.R., Rylander, L.: Factors influencing the decision to extend working life or retire. Scand. J. Work Environ. Health 37(6), 473-480 (2011). https://doi.org/10.5271/sjweh.3181

Nübling, M., Andersen, H.H., Mühlbacher, A.: Data Documentation 16. Entwicklung eines Verfahrens zur Berechnung der körperlichen und psychischen 
Summenskalen auf Basis der SOEP - Version des SF 12 (Algorithmus), Berlin (2006)

Oakman, J., Neupane, S., Proper, K.I., Kinsman, N., Nygård, C.-H.: Workplace interventions to improve work ability: a systematic review and metaanalysis of their effectiveness. Scand. J. Work Environ. Health 44(2), 134-146 (2018). https://doi.org/10.5271/sjweh.3685

Rauch, A., Burghardt, A., Eggs, J., Tisch, A., Tophoven, S.: lidA-leben in der Arbeit. German cohort study on work, age and health. J. Labour. Market Res. 48(3), 195-202 (2015). https://doi.org/10.1007/s12651-015-0189-2

Roe, R.A.:Time in applied psychology. Eur. Psychol. 13(1), 37-52 (2008). https:// doi.org/10.1027/1016-9040.13.1.37

Rongen, A., Robroek, S.J.W., van der Heijden, B.I.J.M., Schouteten, R., Hasselhorn, H.M., Burdorf, A.: Influence of work-related characteristics and work ability on changing employer or leaving the profession among nursing staff. J. Nurs. Manage. 22(8), 1065-1075 (2014). https://doi.org/10.1111/ jonm.12066

Rubenstein, A.L., Eberly, M.B., Lee, T.W., Mitchell, T.R.: Surveying the forest: a meta-analysis, moderator investigation, and future-oriented discussion of the antecedents of voluntary employee turnover. Pers. Psychol. 71(1), 23-65 (2018). https://doi.org/10.1111/peps.12226

Sanders, J., Dorenbosch, L., Gründemann, R., Blonk, R.: Sustaining the work ability and work motivation of lower-educated older workers: directions for work redesign. Manage. Revue. 22(2), 132-150 (2011). https://doi.org/ 10.5771/0935-9915-2011-2-132

Tuomi, K., Toikkanen, J., Eskelinen, L., Backman, A.L., Ilmarinen, J., Jarvinen, E., Klockars, M.: Mortality, disability and changes in occupation among aging municipal employees. Scand. J. Work. Environ. Health 17(1), 58-66 (1991)
Tuomi, K., Ilmarinen, J., Seitsamo, J., Huuhtanen, P., Martikainen, R., Nygard, C.-H., Klockars, M.: Summary of the Finnish research project (1981-1992) to promote the health and work ability of aging workers. Scand. J. Work Environ. Health 23(1), 66-71 (1997)

van den Berg, T.I.J., Alavinia, S.M., Bredt, F.J., Lindeboom, D., Elders, L.A.M., Burdorf, A.: The influence of psychosocial factors at work and life style on health and work ability among professional workers. Int. Arch. Occup. Environ. Health 81(8), 1029-1036 (2008). https://doi.org/10.1007/ s00420-007-0296-7

Ware, J.E., Kosinski, M., Keller, S.D.: SF-12: how to score the SF-12 physical and mental health summary scales, 2nd edn. The Health Institut, New England Medical Center, Boston (1995)

Ware, J.E., Kosinski, M., Keller, S.D.: A 12-item Short-Form Health Survey: construction of scales and preliminary tests of reliability and validity. Med. Care. 34(3), 220-233 (1996)

Weale, V.P., Wells, Y., Oakman, J.: The relationship between workplace characteristics and work ability in residential aged care: what is the role of work-life interaction? J. Adv. Nurs. 75(7), 1427-1438 (2019). https://doi.org/10. 1111/jan.13914

Wilke, C., Portnicki, M., Froböse, I., Biallas, B.: Steigerung der ArbeitsfähigkeitEntwicklung eines Konzepts im Rahmen des betrieblichen Gesundheitsmanagements. Präv. Gesundheitsf. 14(4), 392-397 (2019). https://doi.org/ 10.1007/s11553-019-00709-4

\section{Publisher's Note}

Springer Nature remains neutral with regard to jurisdictional claims in published maps and institutional affiliations.

\section{Submit your manuscript to a SpringerOpen ${ }^{\circ}$ journal and benefit from:}

- Convenient online submission

- Rigorous peer review

- Open access: articles freely available online

- High visibility within the field

- Retaining the copyright to your article

Submit your next manuscript at $\boldsymbol{\nabla}$ springeropen.com 